\title{
MODELLING THE MESHING OF CYCLOIDAL GEARS
}

\author{
Jerzy NACHIMOWICZ*, Stanisław RAFAŁOWSKI ${ }^{*}$
}

*Bialystok University of Technology, Department of Mechanical Engineering, Faculty of Mechanical Engineering, ul. Wiejska 45C, 15-351 Białystok, Poland

j.nachimowicz@pb.edu.pl, s.rafalowski90@gmail.com

received 16 June 2015, revised 11 May 2016, accepted 16 May 2016

\begin{abstract}
Cycloidal drives belong to the group of planetary gear drives. The article presents the process of modelling a cycloidal gear. The full profile of the planetary gear is determined from the following parameters: ratio of the drive, eccentricity value, the equidistant (ring gear roller radius), epicycloid reduction ratio, roller placement diameter in the ring gear. Joong-Ho Shin's and Soon-Man Kwon's article (Shin and Know, 2006) was used to determine the profile outline of the cycloidal planetary gear lobes. The result was a scatter chart with smooth lines and markers, presenting the full outline of the cycloidal gear.
\end{abstract}

Key words: Cycloidal Drive, Modelling, Profile, Planetary Gear, Gear

\section{INTRODUCTION}

Analysis of the function of the cycloidal transmission indicates that it is a rolling transmission, in which all elements move along a circle (Rutkowski, 2014). Because of its specific design, cycloidal gears have many advantages, such as: a wide range single stage reductions (even up to 170), making the drive relatively small, high mechanical efficiency, and silent operation. Moreover, its minimal moment of inertia results in smooth start and allows fast change of movement direction. The drive also has a significant overload capacity and reacts quickly to change of load (Chmurawa, 2002; Bednarczyk, 2014).

Cycloidal gear stands out among all gears with its lower mass, smaller housing and its quietness. These are the advantages in machines that demand high gear ratio. In the current planetary gears, for getting enough reduction, three drive ratios are needed. It leads planetary gears to getting bigger and heavier with every drive ratio added. In cycloidal gears only two drive ratios are needed to get planetary gear reduction with three drive ratios. Moreover, inner clearances helps cycloidal gear to provide super precise movement in machinery.

Due to their advantages, cycloidal drives are becoming increasingly popular in modern industry, and are used in wood processing machines, CNC and machine tool workshops, technical head drives, as well as glass and textile machines.

The gears are also used in robot arm joints, hoists and turntables. However, the development and spread of cycloidal drives is not as dynamic as in the case of other similar devices. This is because constructing cycloidal drives is not an easy task - their design is highly complicated, and so is the technology of curved meshing of planetary gears. Also, producers of machinery which uses these type of drives do not share their designs (Chmuraa, 2002; Siczek and Warda, 2008; Yan and Lai, 2002; Feng and Litvin, 1996; Kabaca, 2013; Bednarczyk, 2013; Blagojevic et al., 2012; Hwang and Hsieh, 2007; Meng et al., 2007; Figliolinii et al., 2013; Sung and Tsai, 1997; Hong-Liu et al., 2013; Wand and Song, 2008).

Therefore, it was necessary to demonstrate the process of modelling a toothed gear with a cycloidal profile.

\section{EQUATIONS DESCRIBING THE PROFILE OF A CYCLOIDAL GEAR}

Modelling a cycloidal gear is possible with equations $(1,2)$ presented in an article by Shin and Kwon (2006):

$$
\begin{aligned}
& B_{x}=r \cdot \cos (\varphi)-q \cdot \cos (\varphi+\Psi)-e \cdot \cos (N \varphi) \\
& B_{y}=-r \cdot \sin (\varphi)+q \cdot \sin (\varphi+\Psi)+e \cdot \sin (N \varphi)
\end{aligned}
$$

where: $r$ - distance between the ring gear rollers [mm]; $q \varphi$ radius of the ring gear roller [mm]; $N$ - number of rollers of the ring gear; $e$ - eccentricity value $[\mathrm{mm}] ; \psi$ - contact angle between the roller and the lobe of the cycloid gear [0]; $\varphi$ - angle between point $B$ and the $x$ axis in the central point of the coordinate system [0].

The contact angle between the roller and the lobe of the cycloid gear is determined from the following equation:

$\Psi=\operatorname{atan}\left[\frac{\sin [(1-N) \varphi]}{\frac{r}{e N}-\cos [(1-N) \varphi]}\right]$

$$
\left(0^{\circ} \leq \varphi \leq 360^{\circ}\right)
$$

In order to determine the curvature profile of the cycloidal gear, the coordinates of multiple B points must be determined, which form the shape of the gear (Fig. 1). The equations $(1,2)$ make it possible to determine the coordinates of point $b$ for any angle $\varphi$. The precision of the profile depends on the step value of angle $\varphi$ the smaller the step is, the corresponding shape is more precise. What is characteristic about these equations is that there is always one less lobe of the cycloidal gear than there are rollers in the ring gear. 


\section{MODELLING THE PROFILE OF THE CYCLOIDAL GEAR}

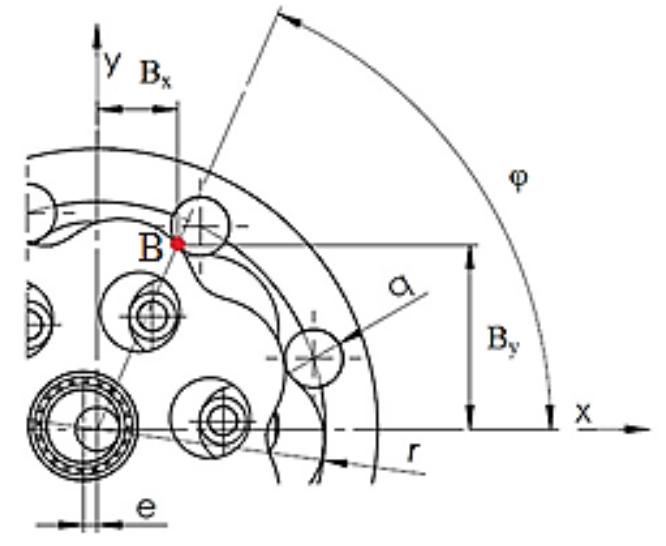

Fig. 1. Cycloidal gear parameters: $r$ - radius of the ring gear; $q$ - radius of the roller; $e$-eccentricity; $\varphi$ - angle between point $B$ and the $x$ axis in the central point of the coordinate system; $B$ - point on curvature profile of the lobe; $B x, B y-$ coordinates of point $B$

\section{GENERAL PROFILE OF THE LOBE OF THE CYCLOIDAL GEAR}

Fig. 2 presents the outline of the lobe of the cycloidal gear. In order to form the shape of the lobe, the number of points was set at $k=95$ with coordinates $B=(B i x, B i y)$. After determining the positions of all points against the beginning of the coordinate system, the points are connected with a spline.

As the profile of the cycloidal gear must be very precise, two additional points were added at both ends, whose position was determined for adjacent lobes of the gear.

This assumption is presented in equation:

$\mathrm{w} \in<-2 ; \mathrm{k}+3>\in \mathrm{C}$

where: $w$-number of point; $k$-number of points per each lobe of the gear; $C$ - set of total numbers.

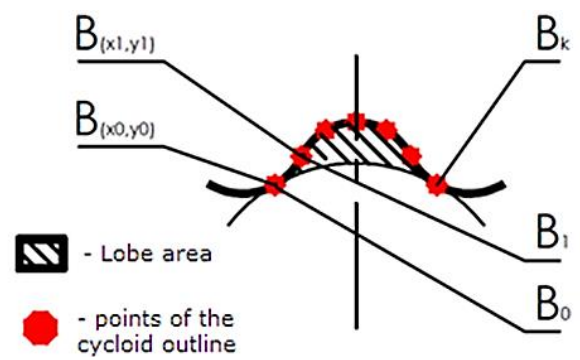

Fig. 2. Lobe profile outline: $B_{0}, B_{1}, B_{k}$ - successive points creating the outline of the lobe; $\mathrm{B}\left(\mathrm{x}_{0}, \mathrm{x}_{0}\right), \mathrm{B}\left(\mathrm{x}_{1}, \mathrm{y}_{1}\right)$ - coordinates for points $\mathrm{B}_{0}$ and $\mathrm{B}_{1}$ respectively
Microsoft Excel was used to make the necessary calculations in order to determine the profile of the cycloidal gear. The spreadsheet presents the basic parameters of a cycloidal drive (Fig. 3), which were then used to determine the additional parameters of the drive with the corresponding equations (Fig. 4).

\begin{tabular}{|c|c|c|c|c|}
\hline 4 & A & B & C & D \\
\hline 1 & \multicolumn{4}{|c|}{ Basic parameters of the cycloidal drive } \\
\hline 2 & $\begin{array}{l}\text { Roller distance in } \\
\text { the ring gear } \\
\mathrm{r}[\mathrm{mm}]\end{array}$ & \begin{tabular}{|c|} 
Eccentricity \\
value \\
e $[\mathrm{mm}]$
\end{tabular} & \begin{tabular}{|c} 
Equidistant \\
$\mathrm{q}[\mathrm{mm}]$
\end{tabular} & $\begin{array}{c}\text { Number } \\
\text { of lobes } \\
\text { z1 }\end{array}$ \\
\hline 3 & 43,64 & 2 & 4 & 11 \\
\hline
\end{tabular}

Fig. 3. Basic parameters of the cycloidal drive required for the calculations

\begin{tabular}{|c|c|c|c|c|c|}
\hline & $\mathrm{E}$ & $\mathrm{F}$ & $\mathrm{G}$ & $\mathrm{H}$ & $\mathrm{I}$ \\
\hline 1 & \multicolumn{5}{|c|}{ Additional parameters of the cycloidal drive } \\
\cline { 2 - 6 } 2 & $\mathrm{Q}$ & $\mathrm{k}$ & $\mathrm{N}$ & reN $>1$ & $\mathrm{~d} \varphi$ \\
\hline 3 & 24 & 95 & 12 & 1,818333333 & 0,344498 \\
\hline
\end{tabular}

Fig. 4. Additional parameters of the cycloidal drive required for the calculations

Equation formulas and the values in individual cells are presented in Tab. 1. When designing the profile of the gear, it is necessary to verify the condition necessary for the drive to work (cell H3), which was set for conditional formatting. When the condition is met, the background of the cell is green - when the condition is not met, it is red.

The next stage of the design is the determination of the lobe profile of the cycloidal gear. To do this, Tab. 2 was created in the spreadsheet which determined the coor-dinates of all points comprising the lobe outline of the cycloidal gear.

The first column of the table lists the indexes of the $B$ points which created the profile of the lobe, beginning in cell $A 19$.

The initial value of the index is -2 , increased by 1 at each step, and the final value is $k+2$, which in this case is 97 . The second column contains the $\varphi$ angle values in radians. The next column calculates the $\Psi$ angle corresponding to angle $\varphi$. The coordinates of the points creating the profile of the lobe are presented in columns $D$ and $E$.

Tab. 1. Formulas and their use in the calculations

\begin{tabular}{|c|c|c|c|c|c|}
\hline Cell & E3 & F3 & G3 & $\mathrm{H} 3$ & 13 \\
\hline Definition & $\begin{array}{c}Q \text { factor introduced in } \\
\text { Shin and Know (2006), } \\
\text { used in the } \\
\text { calculations }\end{array}$ & $\begin{array}{c}k \text { number of } B \text { points } \\
\text { per each lobe of the } \\
\text { gear }\end{array}$ & $\begin{array}{l}N \text { number of rollers } \\
\text { of the ring gear; }\end{array}$ & $\begin{array}{c}\text { drive's functional } \\
\text { condition } \\
\text { (Shin and Know, 2006) }\end{array}$ & $d \varphi$ angle increase \\
\hline Equation & $Q=e \cdot N$ & (assumed value) & $N=z_{1}+1$ & $r /(e \cdot N)>1$ & $d \varphi=360 /\left(z_{1} \cdot k\right)$ \\
\hline Formula & $=B 3 \cdot G 3$ & $=95$ & $=D 3+1$ & $=A 3 /(B 3 \cdot G 3)$ & $=360 /(D 3 \cdot F 3)$ \\
\hline
\end{tabular}


Tab. 2. Equation formulas for cycloidal points

\begin{tabular}{|c|c|c|c|c|c|}
\hline & $A$ & $B$ & $C$ & $D$ & $E$ \\
\hline 18 & $\boldsymbol{k}$ & $\varphi$ & $\Psi$ & $B x$ & By \\
\hline 19 & -2 & $\begin{array}{l}\text { RADIANS (A19 } \\
\cdot 0,344498\end{array}$ & $\begin{array}{l}\operatorname{ATAN}((\operatorname{SIN}(-11 \\
\cdot B 19)) /(1,818-\operatorname{COS}(-11 \\
\cdot B 19)))\end{array}$ & $\begin{array}{l}43,64 \cdot \operatorname{COS}(B 19)-4 \\
\cdot \operatorname{COS}(B 19+B 20)-2 \\
\cdot \operatorname{COS}(12 \cdot B 19)\end{array}$ & $\begin{array}{l}-43,64 \cdot \operatorname{SIN}(B 19)+4 \\
\cdot \operatorname{SIN}(B 19+B 20)+ \\
2 \cdot \operatorname{SIN}(12 \cdot B 19)\end{array}$ \\
\hline
\end{tabular}

Tab. 3. Equation formulas for the full outline

\begin{tabular}{|c|c|c|c|c|c|}
\hline & $\mathrm{F}$ & $G$ & $\mathrm{H}$ & 1 & $\mathrm{~J}$ \\
\hline 18 & $\varphi[0]$ & $\varphi$ [rad] & $\Psi$ & $B x(\varphi)$ & $B y(\varphi)$ \\
\hline 19 & 0,2 & RADIANS(F19) & $\begin{array}{c}\operatorname{ATAN}((\operatorname{SIN}(-11 \cdot G 19)) \\
/ \\
(1,818-\operatorname{COS}(-11 \\
\cdot G 19)))\end{array}$ & $\begin{array}{l}43,64 \cdot \cos (G 19)-4 \\
\cdot \operatorname{CoS}(G 19+H 19)-2 \\
\cdot \cos (12 \cdot G 19)\end{array}$ & $\begin{array}{c}-43,64 \cdot \operatorname{SIN}(G 19)+4 \cdot \\
\operatorname{SIN}(G 19+H 19)+2 \cdot \\
\operatorname{SIN}(12 \cdot G 19)\end{array}$ \\
\hline
\end{tabular}

The results of the calculations were put in a scatter chart with smooth lines and markers, presenting the outline of the cycloidal gear lobe (Fig. 5).

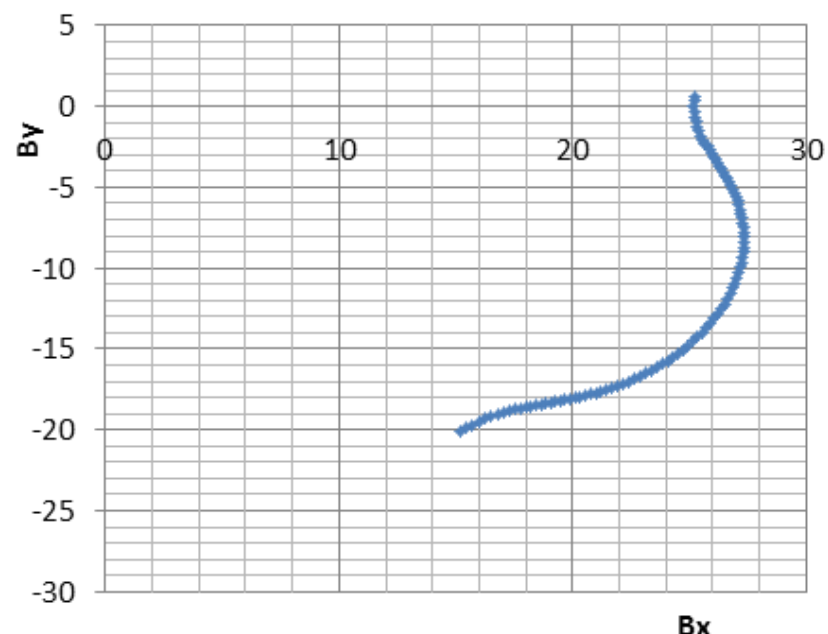

Fig. 5. Lobe profile in a coordinate system

The last stage of designing the cycloidal gear is determining its complete outline. Tab. 3 was created analogously to determining the position of the cycloidal gear lobe. The only difference is that the angle $\varphi$ (columnt F), expressed in degrees, was used instead of the $k$ point index.

The coordinates of the points on the outline curve were calculated for full $360^{\circ}$. To determine a very accurate contour of the cycloidal gear, the step angle of angle $\varphi$ was $0.2^{\circ}$. Column $\mathrm{G}$ expresses the values from column $\mathrm{F}$ in radians. The next column presents the values of angle $\Psi$ for corresponding angles from column $\mathrm{G}$. The values of coordinates $B x(\varphi)$ and $B y(\varphi)$ were calculated and listed in columns $I$ and $\mathrm{J}$ respectively.

The results of the calculations were put in a scatter chart with smooth lines and markers, presenting the full outline of the cycloidal gear (Fig. 6).

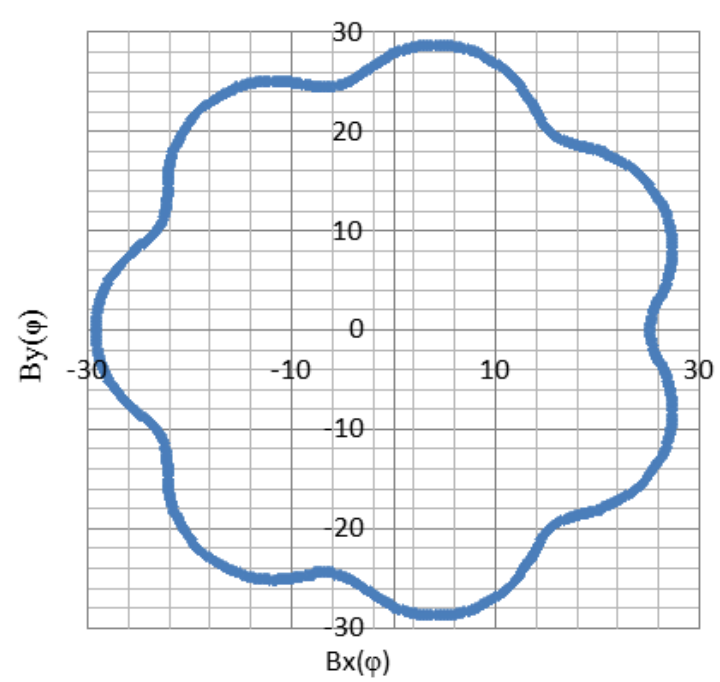

Fig. 6. Full outline of the cycloidal gear

\section{CONCLUSIONS}

Modelling the full outline of the cycloidal gear significantly facilitates the design process of the cycloidal drive. Because the cycloidal gear is an extremely important element of the drive, the precise outlining of the gear's profile is critical in designing the drive - it decides on the proper and stable functioning of the device.

Designing the profile of the cycloidal gear is complex. Due to the complexity of designing of the profile of the cycloidal gear it is necessary to use suitable spreadsheets, for example Microsoft Excel software or other computer aided engineering program like MathCad, Statistica or other 2D plots generators. After inputting all demanded data and assumptions they help getting adequate calculations. Furthermore, they are helpful in fast changing of parameters in prototypes, which is very comfortable and reduces amount of time needed to designing of cycloidal gear.

The main parameters that determine the profile are the eccentricity value, roller radius, as well as the epicycloid reduction ratio. The precision of the outline depends on the angle step of angle $\varphi$. Due to the complexity of the process it is best to do the calculations using computer software. 


\section{REFERENCES}

1. Bednarczyk S. (2013), Cycloidal gear development focused on the transfer of efficiency of the machines, In: Idzikowski A.: Efficiency of working machines and equipment in the industry, Press WZ PCZ, Czestochowa, 117-225.

2. Bednarczyk S. (2014), Determination of the gear geometry of the of the cyclo gear, Silesia University of Technology Scientific Notebooks, Gliwice, 29-39.

3. Blagojevic M., Kocic M., Marjanovic N., Stojanovic B., Dordevic Z., Ivanovic L., Marjanovic V. (2012), Influence of the friction on the cycloidal speed reducer efficiency, Journal of the Balkan Tribological Association, 18(2), 217-227.

4. Chmurawa M. (2002), Cyclo gear meshing with modification, Silesia University of Technology Scientific Notebooks, Gliwice, No. 1547, 2139.

5. Feng P. H., Litvin F. L. (1996), Computerize design and generation of cycloidal gearing, Mechanism and Machine Theory, 31 (7), 891-911.

6. Figliolinii G., Stachel H., Angeles J. (2013), On Martin Disteli's spatial cycloidal gearing, Mechanism and Machine Theory, 60, 73-89.

7. Hong-Liu Y., Jin-Hua Y., Xin H., Ping S. (2013), Study on teeth profile modification of cycloid reducer based on non-Hertz elastic contact analysis, Mechanics Research Communications, 48, 87-92.
8. Hwang Y.-W., Hsieh Ch.-F. (2007), Determination of surface singularities of a cycliodal gear drive with inner meshing, Mathematical and Computer Modelling, 45, 340-354.

9. Kabaca T. (2013), A model teaching for the cycloid curves by the use of dynamic software with multiple representions approach, Academic Journals, Vol. 6(3), 40-50.

10. Meng Y., Wu Ch., Ling L. (2007), Mathematical modeling of the transmision performance of $2 \mathrm{~K}-\mathrm{H}$ pin cycloid planetary mechanism, Mechanism and Machine Theory, 42(7), 776-790.

11. Rutkowski A. (1986), Machinery parts, WSiP, Warsaw, 323-325.

12. Shin J., Know S. (2006), On the lobe profile design in a cycloid reducer using instant velocity center, Mechanism and Machine Theory, 41(5), 487-616.

13. Siczek K., Warda B. (2008), Using of cycloidal gear in car selfstarter, Journal of KONES Powertrain and Transport, 15(4), 509516.

14. Sung L. M., Tsai Y.C. (1997), A study on the mathematical models and contact ratios of extended cycloid and cycloid bevel gear sets, Mechanism and Machine Theory, 32 (1), 39-50.

15. Wang W.-S., Fong Z.-H. (2008), A dual face-hobbing method for the cycloidal crowning of spur gears, Mechanism and Machine Theory, 43(11), 1416-1430.

16. Yan H. S., Lai T. S. (2002), Geometry design an elementary planetary gear train with cylindrical tooth-profiles, Mechanism and Machine Theory, 37(8), 683-686. 